\title{
Surface Cellulose Modification with 2-Aminomethylpyridine for Copper, Cobalt, Nickel and Zinc Removal from Aqueous Solution
}

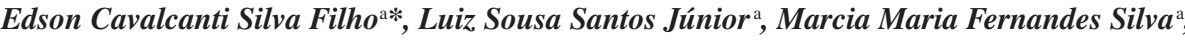 \\ Maria Gardênnia Fonseca ${ }^{\mathrm{b}}$, Sirlane Aparecida Abreu Santana ${ }^{\mathrm{c}}$, Claudio Airoldi ${ }^{\mathrm{d}}$ \\ anterdisciplinary Laboratory for Advanced Materials - LIMAV, \\ Federal University of Piauí - UFPI, CEP 64049-550, Teresina, PI, Brazil \\ ${ }^{\mathrm{b}}$ Chemistry Department, Federal University of Paraíba - UFPI, \\ CEP 58059-900, João Pessoa, PB, Brazil \\ ${ }^{\circ}$ Chemistry Department, Federal University of Maranhão - UFMA, \\ CEP 65080-540, São Luiz, MA, Brazil \\ ${ }^{\mathrm{d}}$ Institute of Chemistry, University of Campinas - UNICAMP, \\ CP 6154, CEP 13084-971, Campinas, SP, Brazil
}

Received: May 25, 2012; Revised: July 24, 2012

\begin{abstract}
Cellulose was first modified with thionyl chloride, followed by reaction with 2-aminomethylpyridine to yield 6-(2'-aminomethylpyridine)-6-deoxycellulose. The resulting chemically-immobilized surface was characterized by elemental analysis, FTIR, ${ }^{13} \mathrm{C}$ NMR and thermogravimetry. From $0.28 \%$ of nitrogen incorporated in the polysaccharide backbone, the amount of $0.10 \pm 0.01 \mathrm{mmol}$ of the proposed molecule was anchored per gram of the chemically modified cellulose. The available basic nitrogen centers attached to the covalent pendant chain bonded to the biopolymer skeleton were investigated for copper, cobalt, nickel and zinc adsorption from aqueous solution at room temperature. The newly synthesized biopolymer gave maximum sorption capacities of $0.100 \pm 0.012,0.093 \pm 0.021$, $0.074 \pm 0.011$ and $0.071 \pm 0.019 \mathrm{mmol} . \mathrm{g}^{-1}$ for copper, cobalt, nickel and zinc cations, respectively, using the batchwise method, whose data was fitted to different sorption models, the best fit being obtained with the Langmuir model. The results suggested the use of this anchored biopolymer for cation removal from the environment.
\end{abstract}

Keywords: cellulose, modification, 2-aminometylpyridine, sorption, cations

\section{Introduction}

The field of surface chemistry describes a variety of natural or synthetic materials suitable for chemical surface reactions, with the main objective to improve the overall capacity for applications ${ }^{1,2}$. A lot of these supports are derived from inorganic compounds, such as silica and other oxides, however, some important reports describe excellent results in which are related to biopolymers ${ }^{3-5}$. In this sense, the most abundant biopolymer is cellulose, but, the effectiveness of its applications is associated with new synthesized polymers after chemical surface modifications, by incorporating desired molecules that possess functional groups, which are, in general, Lewis basic sites, with the investigations normally focused on sorption processes ${ }^{6-8}$. One of the most known synthetic methods is based on preparing, in the first step, a halogen derivative ${ }^{9}$, by including it on the original polymeric structure at carbon 6, as shown in Figure 1.

Biopolymer halogenation is preferred due to the fact that chlorine is the mosteffective halogen, whose preferential sequence is given as follows: chlorine $>$ bromine $>$ iodine $>$ fluorine. Then, the effectiveness of such reaction routes has been

*e-mail: edsonfilho@ufpi.edu.br explored by using different chemicals as precursors, with the objective of transferring this element to the cellulosic polymeric chain. A series of other reactants are available for such process, but thionyl chloride is the most effective and, consequently, is the most used ${ }^{10}$, followed by phosphoryl oxychloride ${ }^{11}$, N-chlorosuccinimide ${ }^{12}$ and tosyl chloride ${ }^{13}$.

The next step of the chemical modification occurs by nucleophilic attack, which is provided by organic molecules embracing basic centers to act as chelating agents in the corresponding structure, such as nitrogen, sulfur, oxygen and/or phosphorous atoms. As mentioned before, these Lewis bases present great efficiency for aqueous metal ion removal $^{6-8}$. However, functional basic groups attached to the pendant chains have also been employed for other important applications $s^{9,14-18}$.

Oxidation is another systematic process to incorporate organic moieties containing functional groups in this fantastic biopolymer that can be performed through esterification and also etherification reactions. In the first case, the reaction usually takes places on carbons 2 and 3, unlike halogenation that occurs preferentially at carbon 6 , and it is also used as an intermediate step for the 


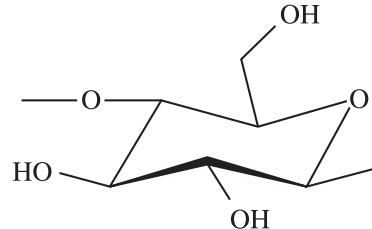

\section{$+\quad \mathrm{SOCl}_{2}$}

$\mathrm{OH}$

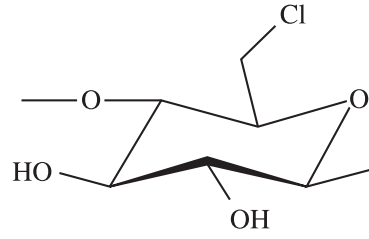

Figure 1. Chlorination of cellulose using thionyl chloride.

incorporation of other functional groups. However, both chemical processes follow the same route as halogenations, through reaction on carbon 6 , with greatest advantage being the occurrence of only one step ${ }^{19}$. The molecule chosen to be immobilized has a chlorine atom that will react with the hydroxyl group, releasing hydrochloric acid to form the ether or ester bonds ${ }^{20}$. Besides, acylation has also been widely investigated as a cellulose surface modification reaction, starting from a cyclic organic in which all three structural hydroxyl groups are involved. In this case, the nucleophilic agents attack the carbonyl group of the strained anhydrides to yield ester bonds, being the most important advantage the absence of halogens in the final structure, without releasing hydrochloric acid ${ }^{21-23}$.

In recent years, the use of the materials based on Green Chemistry principles has been widely investigated in order to reduce the emission of pollutants from the synthetic procedures, as solvents and co-products. Thus, some investigations have already demonstrated solvent-free syntheses are desirable and the amount of organic groups immobilized under these conditions has increased ${ }^{6,7,21-25}$.

Regarding the application of natural or synthetic materials, many pristine or chemically modified polymeric compounds have been extensively applied for cation removal from aqueous solutions and these processes can provide large amounts of metal ion retention or ion exchange processes. In this context, a lot of investigated materials with excellent sorption properties are those on synthetic mesoporous silicas and silica gel supports ${ }^{26-28}$, chemically modified phyllosilicates ${ }^{29-31}$, chitosan, as obtained and after modification with a series of pendant chains ${ }^{24,32,33}$, synthetic phosphates $^{34,35}$, chemically modified celluloses ${ }^{6-8,21-23}$ and others $^{36-38}$. These inorganic or biopolymer materials research fields are continuously expanding, however, the biopolymers, and specially cellulose, have a huge advantage, since they are quite abundant in nature, renewable, biodegradable and easily obtained at low cost.

The simple presence of metals as extra components in nature, in a variety of forms, has encouraged finding solutions for this problem, especially when they are discharged directly to soil or to ground water. Domestic, industrial and agricultural residues are pollutant sources, which can reach not only potable water, but also the alimentary chain, affecting the entire ecosystem. In addition, the toxicity of a variety of metals in aquatic organisms has awakened and focused biological interest. Based on this unfavorable condition, efforts are focused to sorb trace metals using natural materials that can perform an important role in these species determinations in aqueous systems. Therefore, these concerns are part of an organized society that is worried about the welfare of the community and any material is welcome to apply for such applications ${ }^{1,6}$. Although sorption is the most frequently used method, due to its low cost and possible support reuse, among other factors, other methods have been used for cation removal from aquatic environments, such as ion exchange ${ }^{39,40}$, electrodeposition $^{41,42}$, precipitation ${ }^{43,44}$, coagulation and flocculation ${ }^{45,46}$, among others.

The present investigation deals with chemically modified cellulose, after incorporating the 2-aminomethylpyridine moiety as a pendant functional chain, which is covalently bound to the polymeric framework. These attached nitrogen atoms in the pendant chains are potential sites to bond cations from aqueous solution in a heterogeneous system, whose interactive processes are followed at the solid/liquid interface.

\section{Material and Methods}

\subsection{Materials and apparatus}

Cellulose (Merck), thionyl chloride (Chemika), N,N'-dimethylformamide (Synth), ammonium hydroxide (Aldrich) and 2-aminomethylpyridine (Aldrich) were used as received. Cation solutions were prepared from reagent grade nitrates (Vetec).

The amount of 2-aminomethylpyridine pendant chains anchored onto the cellulose surface was calculated based on the percent of nitrogen, determined through elemental analysis on a Perkin Elmer, model 2400, elemental analyzer. The infrared spectra of the samples were obtained in $\mathrm{KBr}$ pellets by accumulating 32 scans on a Bomem spectrophotometer, MB-series, in the $4000-400 \mathrm{~cm}^{-1}$ range with $4 \mathrm{~cm}^{-1}$ resolution. Solid state nuclear magnetic resonance spectra of the samples for carbon were obtained on a Bruker AC 300/P spectrometer at room temperature. For each run, approximately one gram of each solid sample was compacted into a $7 \mathrm{~mm}$ zirconium oxide rotor. The measurements were obtained at $75.47 \mathrm{MHz}$ frequencies with a magic angle spinning of $4 \mathrm{kHz}$. In order to increase the signal to noise ratio the CP/MAS technique was used, with pulse repetition of $2 \mathrm{~s}$ and contact times of 1 and $2 \mathrm{~ms}$, respectively. The thermogravimetric curves in an argon atmosphere were obtained on a TA instrument, coupled to a thermobalance, model $1090 \mathrm{~B}$, using a heating rate of $0.167 \mathrm{~K} . \mathrm{s}^{-1}$, with a flow of $30 \mathrm{~cm}^{3} \cdot \mathrm{s}^{-1}$, varying from room temperature to $1273 \mathrm{~K}$, with an initial mass of approximately $10 \mathrm{mg}$ of solid sample. The amount of cation sorbed was determined by the difference between the initial concentration in the aqueous solution and that found in the supernatant, by using an ICP OES Perkin Elmer 3000 DV apparatus. For each experimental point, the repetivity was checked by at least one duplicate run. 


\subsection{Preparation of modified biopolymer}

For chlorodeoxycellulose synthesis, $10.0 \mathrm{~g}$ of cellulose (Cel), previously activated at $353 \mathrm{~K}$ for 12 hours, was suspended in $200 \mathrm{~cm}^{3}$ of N,N-dimethylformamide (DMF), followed by the slow addition of $35.0 \mathrm{~cm}^{3}$ of thionyl chloride $\left(\mathrm{SOCl}_{2}\right)$ at $353 \mathrm{~K}$, under mechanical stirring. After ending the addition, stirring was continued at the same temperature for another 4 hours. From this reaction the cellulose chloride obtained was washed with several portions of dilute ammonium hydroxide solution and the supernatant in each operation was eliminated to return to neutral $\mathrm{pH}$. To complete the washing, the suspension was exhaustively treated with distilled water. The solid was then filtered and dried under vacuum at room temperature ${ }^{9}$, giving 6-chlorodeoxycellulose (CelCl). Then, $1.0 \mathrm{~g}$ of this synthesized chlorinated biopolymer was reacted with $14.6 \mathrm{~cm}^{3}$ of 2-aminomethylpyridine (amp) under reflux and with mechanical stirring for 4 hours, followed by filtration, using a sintered glass filter. The new solid obtained (Celamp) was dried in vacuum at room temperature for 24 hours $^{8}$.

\subsection{Sorption}

The capacity of the chemically modified cellulose to sorb cations from aqueous solution, in deionized water with $\mathrm{pH}$ near to 6 , was determined in duplicate runs, using a batch process with divalent copper, cobalt, nickel and zinc, by using a mass (m) of about $30 \mathrm{mg}$ of Celamp suspended in $25.0 \mathrm{~cm}^{3}$ of an aqueous solution with concentrations of each metal varying from 0.10 to $5.0 \mathrm{mmol} . \mathrm{dm}^{-3}$. These suspensions were mechanically stirred for 4 hours at room temperature and separated by centrifugation for 10 minutes. The supernatants were pipetted and the cations were determined by ICP OES. The sorption capacities $\left(\mathrm{N}_{f}\right)$ were calculated by considering: $N_{f}=\left(n_{i}-n_{s}\right) \cdot m^{-1}$, where $n_{i}$ and $n_{s}$ are the number of moles in the initial and supernatant solutions ${ }^{25}$.

The sorption at the solid/liquid interface demands a competition between the solvent (solv) bonded to the anchored surface (AS) that is gradually displaced by the solute in solution to reach equilibrium:

$\mathrm{AS}_{(\text {solv })}+\mathrm{M}_{(\text {solv })}^{2+}=\mathrm{AS} . \mathrm{M}^{2+}{ }_{(\text {solv })+}$ solv

To determine the maximum capacity, $N_{s}$, the experimental data related to the number of moles in the supernatant for each point, $C_{s}$, and the $N_{f}$ obtained were fitted to a modified Langmuir equation, with $\mathrm{b}$ being a constant associated with the chemical equilibrium at the solid/liquid interface ${ }^{47}$.

$N_{f}=\frac{b N_{s} C_{s}}{1+b C_{s}}$

The Freundlich equation used to obtain the sorption parameters ${ }^{48}$ is given by the expression:

$N_{f}=K_{f} C_{s}^{\frac{1}{n_{f}}}$

where $n_{f}$ represents the reactivity of energetic sites of the biomaterial and $K_{f}$ is a constant related to the chemical equilibrium at the solid/liquid interface. Another procedure applied to this same equilibrium was the Temkin model ${ }^{49}$, in which $N_{f}$ is calculated:
$N_{f}=\frac{1}{n_{T}} \ln K_{T}+\frac{1}{n_{T}} \ln C_{S}$

As observed, the three classic overall isotherm models are normally applied for sorption surface equilibria, with the solute under study most often measured with batchwise procedures. The amount sorbed is plotted as a function of the remaining solute concentration. Thus, the evaluation of the isotherm parameters is clearly obtained by the coefficient of determination, which value indicates the goodness of the fit between the data and the chosen isotherm.

The data obtained for solute/surface interaction in this heterogeneous system can be interpreted through the models: i) the Langmuir model assumes that similar energy of sorption sites are gradually saturated in a monolayer behavior, ii) the Freundlich model establishes the same sorption process that occurs in a multilayer condition and iii) the Temkin model admits both possibilities in solute sorbing on the surface at the same time.

In the present case, the sorption models were compared through three statistical methods. The first considers the correlation coefficient (r) obtained by means of linear regression of each equation, with a scaling factor derived by the division of each individual deviation with the standard deviation of the corresponding variable, data which was calculated in a specific program.

\section{Results and Discussion}

The cellulose chemically modified with 2 -aminomethylpyridine gave from nitrogen elemental analysis, a value of $0.28+0.02 \%$ that corresponds to the degree of immobilization of $0.10+0.01 \mathrm{mmol}$ of this element per gram of cellulose. Based on chlorine elemental analysis a significant reduction of the amount of chlorine in the preceding chlorated precursor was observed from 17.58 to $8.61 \%$. This reduced value is due to the molar mass of aminopyridine incorporated on the biopolymer, which result shows cellulose functionalization. The incorporated amount was low when compared to other matrices, but within the expected value, when the same molecule was immobilized, for example, onto silica-chloropropyl, it presented close results ${ }^{50}$. This fact can be explained by the steric hindrance caused by the hydrophobicity of this molecule.

The infrared spectra of the crude cellulose and the modified biopolymers are shown in Figure 2. Typical wavenumbers for hydroxyl groups for $\mathrm{Cel}$, such as $-\mathrm{CH}-\mathrm{OH}$ and $-\mathrm{CH}_{2}-\mathrm{OH}$ stretching in the 3300 to $3400 \mathrm{~cm}^{-1}$ interval, are shown in Figure 2a. The methylene group stretchings from the incorporated molecule are located at $2900 \mathrm{~cm}^{-1}$ and the band in the 3000 to $2800 \mathrm{~cm}^{-1}$ range is attributed to the presence of $-\mathrm{C}-\mathrm{H}$ groups, since both $-\mathrm{CH}$ and $-\mathrm{CH}_{2}$ group ratio for cellulose is in a 5:1 proportion ${ }^{6,51,52}$. The $\mathrm{OH}$ bending vibrations for the cellulose surface are located at $1639 \mathrm{~cm}^{-1}$, which differs from primary and secondary hydroxyl bending that appears in the 1500 to $1200 \mathrm{~cm}^{-1}$ interval, and the $\mathrm{C}-\mathrm{O}$ stretching vibration ${ }^{6,51,52}$ is observed at $1100 \mathrm{~cm}^{-1}$.

The appearance of two new bands at 709 and $752 \mathrm{~cm}^{-1}$ for chlorinated cellulose, as shown in Figure 2b, correspond to the $\mathrm{C}-\mathrm{Cl}$ stretching vibration from the branched part of 
the original polymer. The displacement and decreasing size of the band originally observed in the cellulose at $894 \mathrm{~cm}^{-1}$, as shown in Figure 2a, is shifted to $865 \mathrm{~cm}^{-1}$ for the $\mathrm{CelCl}$ compound. The spectrum of 2-aminopyridine chemically modified cellulose is shown in Figure 2c, in which a decrease of $v(\mathrm{C}-\mathrm{Cl})$ vibration confirmed the effectiveness of the reaction. The vibrations related to aliphatic and aromatic $\mathrm{C}-\mathrm{H}$ did not present significant visualization, due to the overlapping bands. In the 1670 to $1720 \mathrm{~cm}^{-1}$ interval an intense band appeared associated with the axial $\mathrm{C}=--\mathrm{C}$ deformation of the monosubstituted aromatic ring, as well as also to the angular $\mathrm{N}-\mathrm{H}$ deformation that is observed in the 1650 to $1600 \mathrm{~cm}^{-1}$ range. The other bands were little affected by the reaction, as previously observed ${ }^{6,51,52}$.

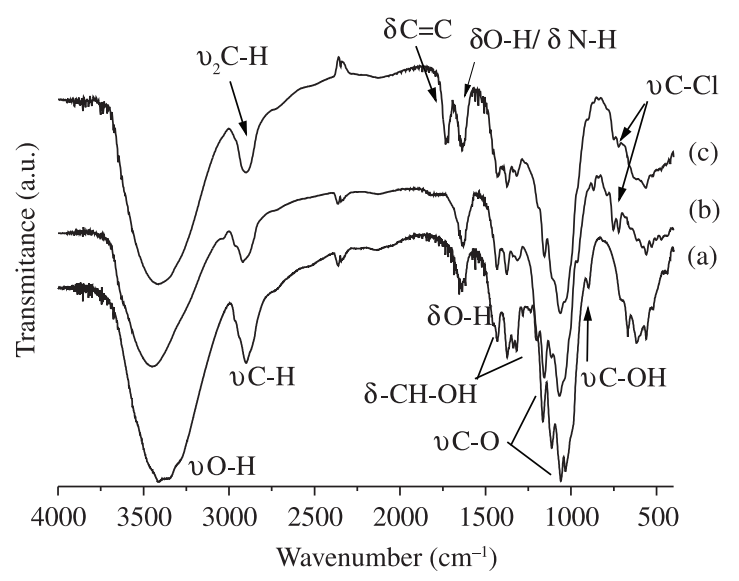

Figure 2. Infrared spectra of Cel (a), $\mathrm{CelCl}$ (b) and Celam (c).
Nuclear magnetic resonance spectrum in the solid state for the carbon nucleus of pure cellulose is presented in Figure 3a. A set of five distinct peaks are present: $\mathrm{C} 1$ at 104 ppm, C4 at 88 ppm, C2, C3, and C5 at 74 ppm, and C6 at $65 \mathrm{ppm}$. For $\mathrm{CelCl}$ several changes in the chemical shifts for $\mathrm{C} 4$ and mainly for $\mathrm{C} 6$ are observed, which are presented at 82 and 44 ppm, respectively, as shown in Figure 3b. For Celam biopolymer, whose spectrum is shown in Figure 3c, a very weak peak in the 170 to $160 \mathrm{ppm}$ interval appeared, due to low immobilized amount anchored, that refers to $\mathrm{C} 8$, in agreement with the low amount immobilized. The presence of a new signal at $65 \mathrm{ppm}$ is also observed that corresponds to the methylene group $\mathrm{C} 7$ of the immobilized molecule, but better visualized than $\mathrm{C} 8$. The other carbons, $\mathrm{C} 9$ to $\mathrm{C} 12$, are not shown, they should appear in the 120 to $150 \mathrm{ppm}$ interval, however, the experimental signal collections were not efficient to demonstrate significant peaks ${ }^{50,52,53}$.

The Celam sample, presented a low crystallinity, with characteristics near to the amorphous form, as shown in the diffractogram in Figure 4b, showing microcrystaline cellulose, with the appearance of peaks in the same region. Thus, as could be observed, the chlorinated cellulose presented a crystallographic profile distinct from microcrystalline cellulose $^{9}$ and the final diffractogram gave close profile to that of the microcrystalline form, as shown in Figure 4a.

The thermogravimetric curves for cellulose and the chemically modified celluloses are shown in Figure 5. For cellulose only one thermal event is observed in the decomposition process in the 536 to $647 \mathrm{~K}$ range, as shown in Figure 5a, with a mass loss of $92 \%$. The chlorinated biopolymer, as shown in Figure 5b, gave a mass loss in the 386 to $430 \mathrm{~K}$ interval, which correlated to the water physically sorbed onto the surface. The second step, with

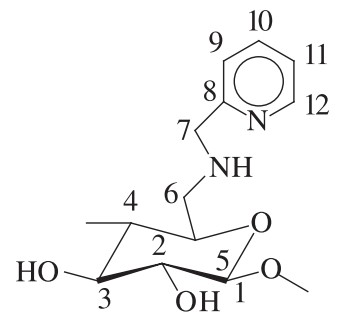

(c)<smiles>COC1OC(CO)(CCl)C(C)(O)C1(C)O</smiles>

(b)

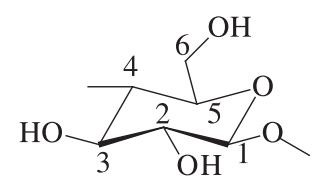

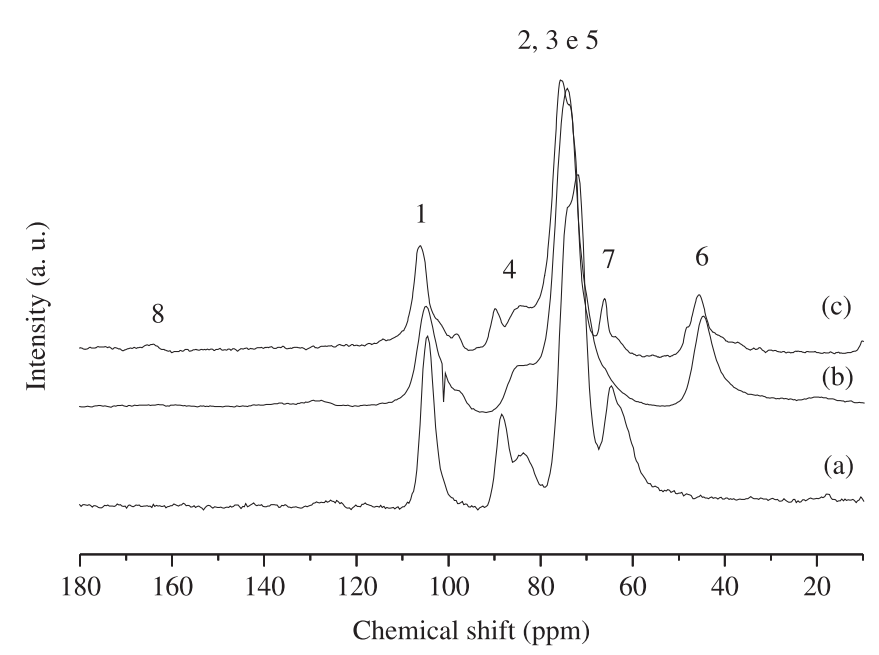

(c)

a)

(a)

Figure 3. ${ }^{13} \mathrm{C}$ NMR of Cel (a), CelCl (b) and Celam (c). 


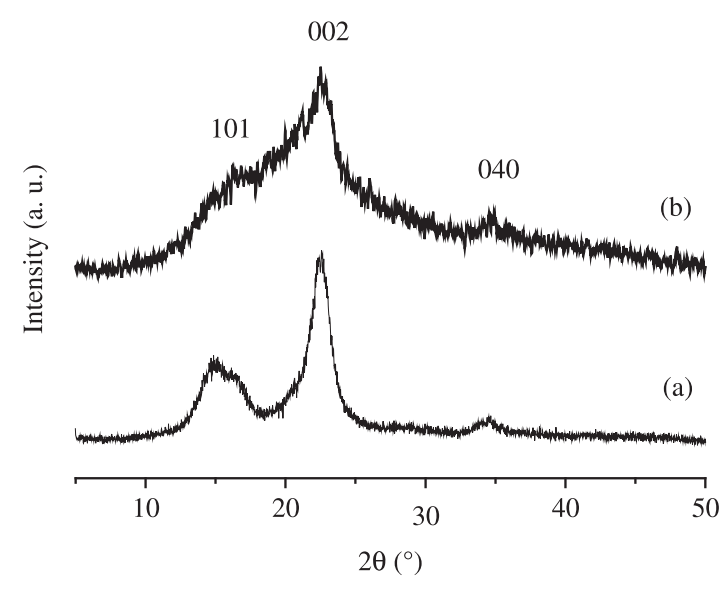

Figure 4. XRD of Cel (a) and Celam (b).

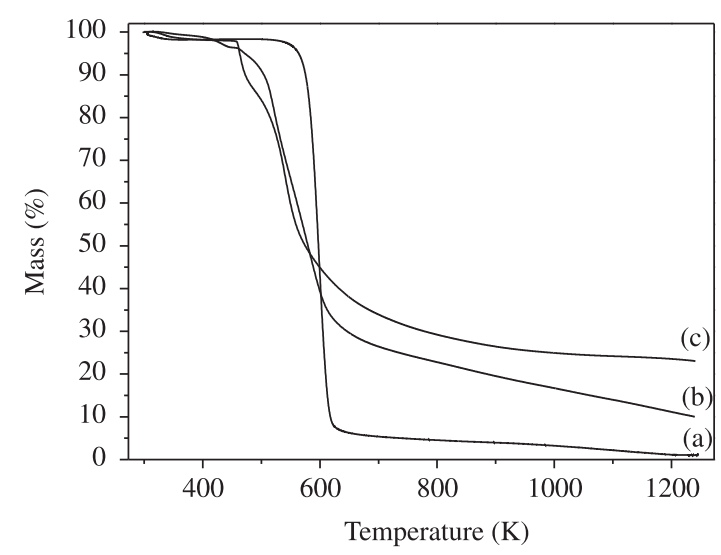

Figure 5. Thermogravimetric curves of $\mathrm{Cel}$ (a), $\mathrm{CelCl}$ (b) and Celam (c).

mass loss of $23 \%$, between 438 and $534 \mathrm{~K}$, corresponds to the displacement of hydrochloric acid, with the condensation of hydroxyl groups on carbons 2 and 3. The last event in this process, from $521 \mathrm{~K}$, can be interpreted as cellulose fiber decomposition. The immobilized biopolymer Celam, as shown in Figure 5c, has a behavior close to the other chemically modified celluloses ${ }^{6,8,22}$, with the same observed events, to give the degradation order: Celam $<\mathrm{CelCl}<\mathrm{Cel}^{54}$.

The sorption isotherms for divalent copper, cobalt, nickel and zinc for cellulose chemically modified with 2-aminopyridine are shown in Figure 6. As observed, the sorption order was the same as for cellulose containing ethylenediamine plus acetylacetone ${ }^{8}$, for this biopolymer chemically modified with butyldiamine $^{7}$ and for other anchored materials ${ }^{50,55,56}$, having maximum sorption values of: $0.100 \pm 0.012,0.093 \pm 0.021$, $0.074 \pm 0.011$ and $0.071 \pm 0.019 \mathrm{mmol} . \mathrm{g}^{-1}$ for $\mathrm{Cu}^{2+}, \mathrm{Co}^{2+}, \mathrm{Ni}^{2+}$ and $\mathrm{Zn}^{2+}$, respectively.

The basic centers ratio available in matrix (B) and the corresponding sorbed amount $(\mathrm{M} / \mathrm{B})$ are listed in Table 1 . In the present biopolymer the $\mathrm{M} / \mathrm{B}$ ratio reached a value very close to one cation for two basic centers in the complexation process, indicating that the pendant chain acted as a bidentate chelating agent. This biopolymer in the present way of complexation used the total capacity

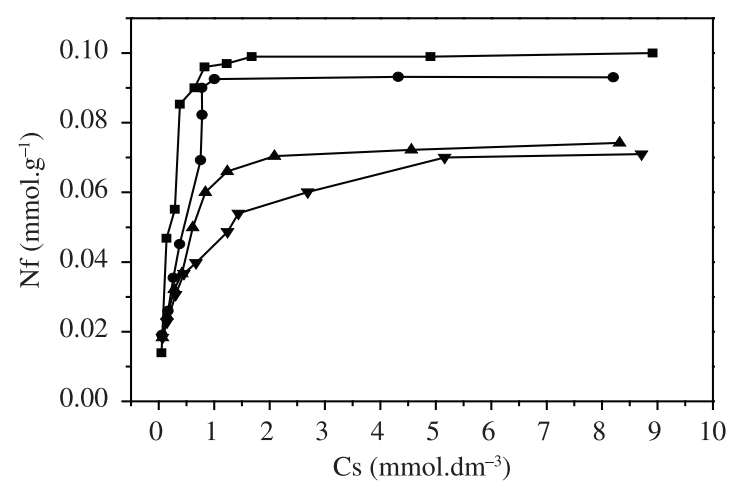

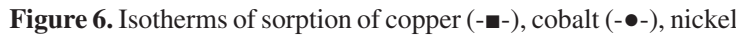
(- $\left.\boldsymbol{\Lambda}_{-}\right)$and zinc (- $\left.\mathbf{\nabla}-\right)$ for Celam at $298 \pm 1 \mathrm{~K}$.

Table 1. Number of moles sorbed $\left(\mathrm{n}_{\mathrm{f}}\right)$ for divalent metals $\left(\mathrm{M}^{2+}\right)$ and divalent metal/basic center ratio $(\mathrm{M} / \mathrm{B})$ for the number of available centers of 0.20 mmol. $\mathrm{g}^{-1}$ for Celam.

\begin{tabular}{ccc}
\hline $\mathbf{M}^{2+}$ & $\mathbf{n}_{\mathbf{f}} / \mathbf{m m o l . g ^ { - 1 }}$ & $\mathbf{M} / \mathbf{B}$ \\
\hline $\mathrm{Cu}$ & $0.100 \pm 0.012$ & $1: 2.0$ \\
$\mathrm{Co}$ & $0.093 \pm 0.021$ & $1: 2.2$ \\
$\mathrm{Ni}$ & $0.074 \pm 0.011$ & $1: 2.8$ \\
$\mathrm{Zn}$ & $0.071 \pm 0.019$ & $1: 2.8$ \\
\hline
\end{tabular}

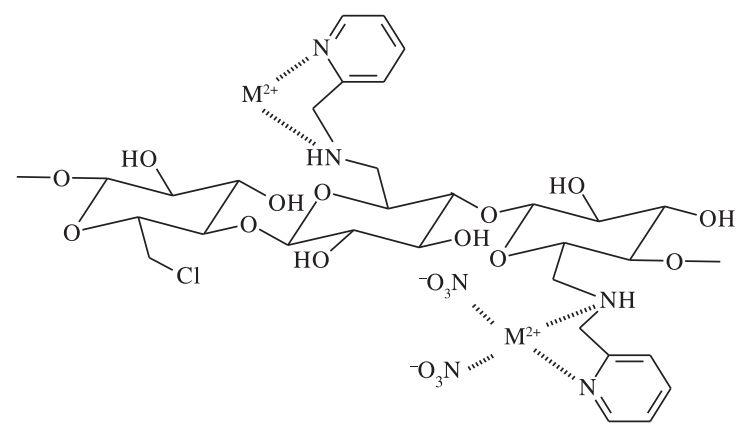

Figure 7. The proposed complexation scheme for divalent cations on Celam.

of the available centers for copper and demonstrated also to be selective for cobalt. A proposed scheme of metal complexation is shown in Figure 7, in which the available basic nitrogen centers coordinate the cations, with the charge being counterbalanced by the counter anions.

The results obtained from the Langmuir, the Freundlich and the Temkim sorption models for these divalent cations with Celam are listed in Table 2 and the new isotherms obtained from the adjusted fit models are shown in Figure 8.

These data show that copper followed by cobalt were the cations with higher sorptions, however, for all cations excellent linear coefficients were obtained when adjusted to the Langmuir model, being values higher than 0.99 . The fit for the Freundlich and the Temkin models gave lower values, which indicated that the isotherms are not well-adjusted to these models. The data obtained for solute/surface interaction in this heterogeneous system 
assumes that similar energy of sorption sites are gradually saturated in a monolayer behavior, to give the good linear fit of experimental data to the Langmuir model. From these results the number of moles for the monolayer proposed by the Langmuir model is close to maximum capacity of sorption. In this condition the sites involved in the sorption process are the basic groups available, which are saturated, especially by copper and in any case, the cations are complexed in a bidentate form, as shown in Figure 7. By comparing the experimental isotherms with one obtained from theoretical calculations, based on the studied models, the results corroborate with the data listed in Table 2, with a better fit to the proposed Langmuir model.

The sorption isotherms, mainly for copper and cobalt, shown in Figure 6, are adjusted to the 2 L type of the Langmuir model, following the Giles classification, with

Table 2. Parameter (Par) data obtained for the Langmuir, the Freundlich and the Temkin models (Model) for divalent cations $\left(\mathrm{M}^{2+}\right)$ on Celam biopolymer.

\begin{tabular}{|c|c|c|c|c|c|}
\hline \multirow{2}{*}{ Model } & \multirow{2}{*}{ Par } & \multicolumn{4}{|c|}{$\mathbf{M}^{2+}$} \\
\hline & & $\mathrm{Cu}$ & Co & $\mathrm{Ni}$ & $\mathbf{Z n}$ \\
\hline \multirow{3}{*}{ Langmuir } & $\mathrm{n}^{\mathrm{s}}$ & 0.102 & 0.097 & 0.077 & 0.075 \\
\hline & $\mathrm{K}^{\mathrm{L}}$ & 0.729 & 0.372 & 0.331 & 0.213 \\
\hline & $\mathrm{r}$ & 0.9995 & 0.9982 & 0.9995 & 0.9986 \\
\hline \multirow{3}{*}{ Freundlich } & $\mathrm{n}_{\mathrm{F}}$ & 3.10 & 2.78 & 3.18 & 3.37 \\
\hline & $\mathrm{K}^{\mathrm{F}}$ & 0.077 & 0.065 & 0.050 & 0.043 \\
\hline & $\mathrm{r}$ & 0.8053 & 0.8742 & 0.9398 & 0.9859 \\
\hline \multirow{3}{*}{ Temkin } & $\mathrm{n}_{\mathrm{T}}$ & 60.61 & 54.88 & 74.18 & 83.26 \\
\hline & $\mathrm{K}^{\mathrm{T}}$ & 158.165 & 52.224 & 55.870 & 50.572 \\
\hline & $\mathrm{r}$ & 0.8702 & 0.8761 & 0.9651 & 0.9919 \\
\hline
\end{tabular}

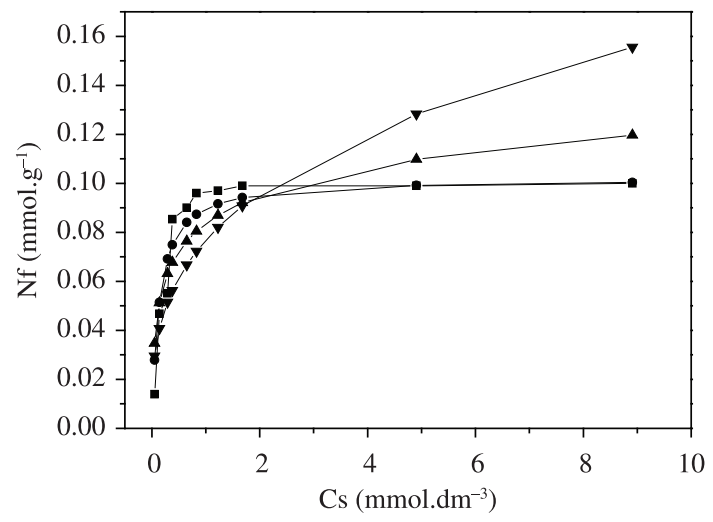

(a)

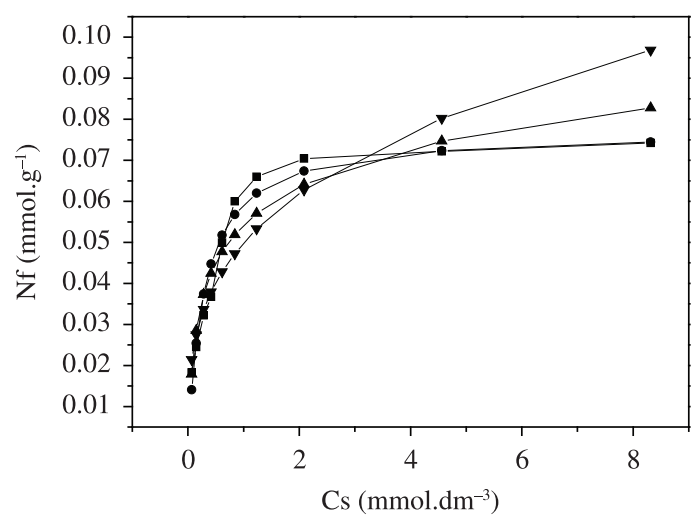

(c)

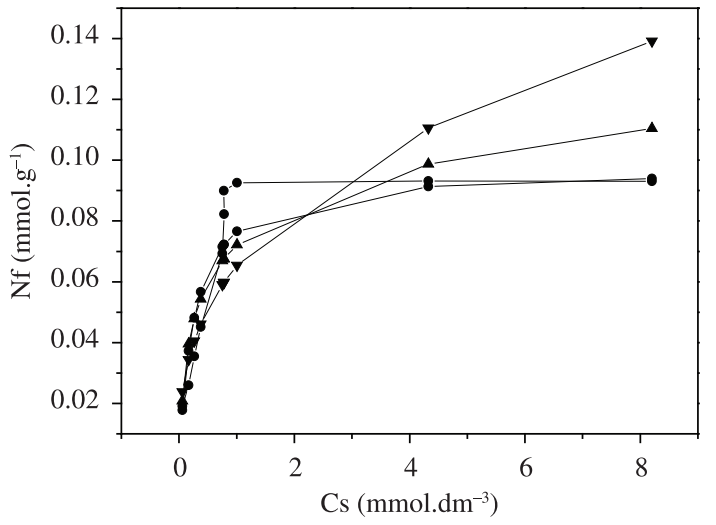

(b)

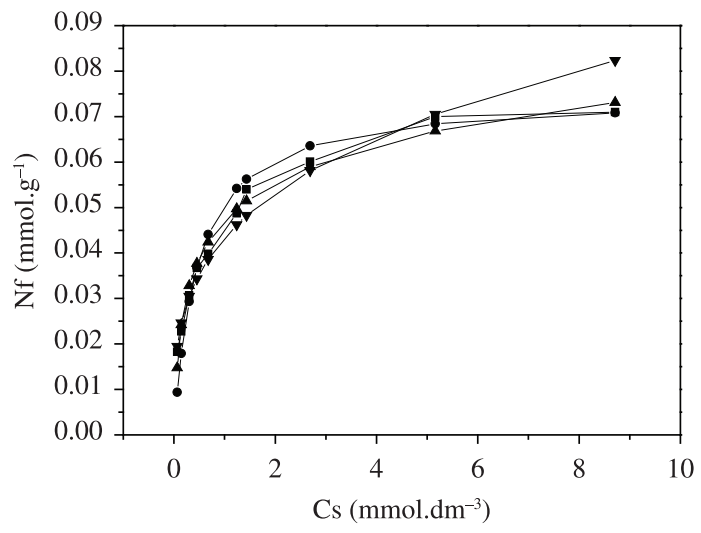

(d)

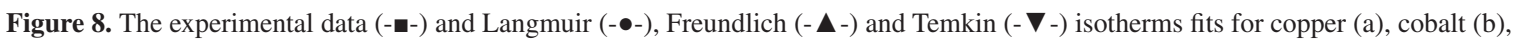
nickel (c) and zinc (d) sorbed on chemically modified cellulose at $298 \pm 1 \mathrm{~K}$. 
a depression concavity, that is, with a slope to reach the plateau, whose behavior is an unequivocal representation of the formed monolayer ${ }^{57}$. These interactions can be interpreted as cation transfer from solution to basic centers attached to the pendant chains, through the complexation by the amino groups at the solid/liquid interface.

The investigation associated with cation removal from aqueous solutions based on the sorption process through metal species complexation, with chemically modified matrices, is of extreme environmental importance as established by Green Chemistry principles ${ }^{58}$, mainly when chemically modified surfaces are presented as efficient for this purpose. These removals from aqueous solution are promising for a series of cations.

\section{Conclusions}

A successful incorporation of the 2-aminomethylpyridine molecule in the absence of solvent onto cellulose is confirmed. Based on elemental analysis, the biopolymer Celam gave a percentage of nitrogen that opposed to the decrease amount of chlorine, after the incorporation of 2-aminomethylpyridine. This result is unequivocal evidence that an effective immobilization of such molecule took place on the cellulose surface. An expressive support for this immobilization is given by the axial $\mathrm{C}=\mathrm{C}$ band related to the aromatic ring in infrared spectroscopy, followed by its chemical shift at $160 \mathrm{ppm}$ from ${ }^{13} \mathrm{C} \mathrm{NMR}$, the change in crystallinity and also by the decomposition profile of the biopolymer.

The anchored biopolymer Celam presented a good capacity in cation removal from aqueous solutions, to give the maximum sorptions of: $0.100,0.093,0.074$ and $0.071 \mathrm{mmol} . \mathrm{g}^{-1}$ in the order $\mathrm{Cu}^{2+}>\mathrm{Co}^{2+}>\mathrm{Ni}^{2+}>\mathrm{Zn}^{2+}$, demonstrating efficiency in complexing cations with a ratio near to $2: 1$, for basic center attached to the pendant chain/cation ratio.

The linearity obtained for the Langmuir fit for the data was higher than other models. As observed, the data shwoed that chemically modified cellulose has higher capacity than the original biopolymer for interacting with cations in solutions, which property can be used in applications in order to reduce the toxic effects of metals in the environment.

\section{Acknowledgements}

The authors are indebted to FAPESP and CNPq for financial support and fellowships.

\section{References}

1. Babel S and Kurniawan TA. Low-cost adsorbents for heavy metals uptake from contaminated water: a review. Journal of Hazardous Materials. 2003; 97:219-243. http://dx.doi. org/10.1016/S0304-3894(02)00263-7

2. Haensch C, Hoeppener S and Schubert US. Chemical modification of self-assembled silane based monolayers by surface reactions. Chemical Society Reviews. 2010; 39:2323-2334. PMid:20424728. http://dx.doi.org/10.1039/b920491a

3. Klemm D, Heublein B, Fink HP and BohnA.Cellulose: fascinating biopolymer and sustainable raw material. Angewandte Chemie International Edition. 2005; 44:3358-3393. PMid:15861454. http://dx.doi.org/10.1002/anie.200460587

4. Kumar MNVR. A review of chitin and chitosan applications. Reactive and Functional Polymers. 2000; 46:1-27. http://dx.doi. org/10.1016/S1381-5148(00)00038-9

5. Moon RJ, Martini A, Nairn J, Simonsen J and Youngblood J. Cellulose nanomaterials review: structure, properties and nanocomposites. Affiliation Information 1. School of Mechanical Engineering,Purdue University, West Lafayette, USA. Chemical Society Review. 2011; 40:3941-3994. PMid:21566801. http://dx.doi.org/10.1039/c0cs00108b

6. Silva Filho EC, Melo JCP and Airoldi C. Preparation of ethylenediamine-anchored cellulose and determination of thermochemical data for the interaction between cations and basic centers at the solid/liquid interface. Carbohydrate Research. 2006; 341:2842-2850. PMid:17022956. http:// dx.doi.org/10.1016/j.carres.2006.09.004

7. Silva Filho EC, Melo JCP, Fonseca MG and Airoldi C. Cation removal using cellulose chemically modified by a Schiff base procedure applying green principles. Journal of Colloid and Interface Science. 2009; 340:8-15. PMid:19748100. http:// dx.doi.org/10.1016/j.jcis.2009.08.012
8. Silva Filho EC, Silva LS, Lima LCB, Santos Júnior LS, Santos MRMC, Matos JME et al. Thermodynamic data of 6-(4 -aminobutylamino)-6-deoxycellulose sorbent for cation removal from aqueous solutions. Separation Science and Technology. 2011; 46:2566-2574. http://dx.doi.org/10.10 80/01496395.2011.599826

9. Silva Filho EC, Santana SAA, Melo JCP, Oliveira FJVE and Airoldi C. X-ray diffraction and thermogravimetry data of cellulose, chlorodeoxycellulose and aminodeoxycellulose. Journal of Thermal Analysis and Calorimetry. 2010; 100:315-321. http://dx.doi.org/10.1007/ s10973-009-0270-6

10. Tashiro T and Shimura Y. Removal of mercuric ions by systems based on cellulose derivatives. Journal of Applied Polymer Science. 1982; 27:747-756. http://dx.doi.org/10.1002/ app.1982.070270235

11. Castro GR, Alcântara IL, Roldan PS, Bozano DF, Padilha PM, Florentino AO et al. Synthesis, characterization and determination of the metal ions adsorption capacity of cellulose modified with p-aminobenzoic groups. Materials Research. 2004; 7:329-334. http://dx.doi.org/10.1590/ S1516-14392004000200018

12. Furuhata KI, Aoki N, Suzuki S, Arai N, Sakamoto M, Saegusa Y et al. Reaction of dichloroallose units in a chlorodeoxycellulose with lithium chloride under homogeneous conditions in N,N-dimethylacetamide. Carbohydrate Research. 1994; 258:169-178. http://dx.doi. org/10.1016/0008-6215(94)84083-0

13. Koschella A and Heinze T. Unconventional cellulose products by fluorination of tosyl cellulose. Macromolecular Symposia. 2003; 197:243-254. http://dx.doi.org/10.1002/ masy. 200350722

14. Jalali N, Moztarzadeh F, Mozafari M, Asgari S, Motevalian M and Alhosseini SN. Surface modification of poly(lactide-co-glycolide) nanoparticles by d-a-tocopheryl 
polyethylene glycol 1000 succinate as potential carrier for the delivery of drugs to the brain. Colloids and Surfaces A. 2011; 392:335-342. http://dx.doi.org/10.1016/j. colsurfa.2011.10.012

15. Asouhidou DD, Triantafyllidis KS, Lazaridis NK and Matis KA. Adsorption of Remazol Red 3BS from aqueous solutions using APTES- and cyclodextrin-modified HMS-type mesoporous silicas. Colloids and Surface A. 2009; 346:83-90. http://dx.doi.org/10.1016/j.colsurfa.2009.05.029

16. Silva ALP, Sousa KS, Germano AFS, Oliveira VV, Espínola JGP, Fonseca MG et al. A new organofunctionalized silica containing thioglycolic acid incorporated for divalent cations removal - a thermodyamic cation/basic center interaction. Colloids and Surface A. 2009; 332:144-149. http://dx.doi. org/10.1016/j.colsurfa.2008.09.010

17. Khan A, Badshah S and Airoldi C. Biosorption of some toxic metal ions by chitosan modified with glycidylmethacrylate and diethylenetriamine. Chemical Engineering Journal. 2011; 171:159-166. http://dx.doi.org/10.1016/j. cej.2011.03.081

18. Khan A, Badshah S and Airoldi C. Dithiocarbamated chitosan as a potent biopolymer for toxic cation remediation. Colloids and Surface B. 2011; 87:88-95. PMid:21652182. http://dx.doi. org/10.1016/j.colsurfb.2011.05.006

19. O'Conell DW, Birkinshaw C and O'Dwyer TF. Heavy metals adsorbents prepared from the modification of cellulose: a review. Bioresource Technology. 2008; 99:6709-6724. PMid:18334292. http://dx.doi.org/10.1016/j.biortech.2008.01.036

20. Ratanakamnuan U, Atong D and Aht-Ong D. Cellulose esters from waste cotton fabric via conventional and microwave heating. Carbohydrate Polymers. 2012; 87:84-94. http://dx.doi. org/10.1016/j.carbpol.2011.07.016

21. Melo JCP, Silva Filho EC, Santana SAA and Airoldi C. Maleic anhydride incorporated onto cellulose and thermodynamics of cation-exchange process at the solid/liquid interface. Colloids and Surface A. 2009; 346:138-145. http://dx.doi.org/10.1016/j. colsurfa.2009.06.006

22. Melo JCP, Silva Filho EC, Santana SAA and Airoldi C. Synthesized cellulose/succinic anhydride as an ion exchanger. Calorimetry of divalent cations in aqueous suspension. Thermochimica Acta. 2011; 524:29-34. http://dx.doi. org/10.1016/j.tca.2011.06.007

23. Melo JCP, Silva Filho EC, Santana SAA and Airoldi C. Exploring the favorable ion-exchange ability of phthalylated cellulose biopolymer using thermodynamic data. Carbohydrate Research. 2010; 345:1914-1921. PMid:20673881. http:// dx.doi.org/10.1016/j.carres.2010.06.012

24. Sousa KS, Silva Filho EC and Airoldi C. Ethylenesulfide as a useful agent for incorporation into the biopolymer chitosan in a solvent-free reaction for use in cation removal. Carbohydrate Research. 2009; 344:1716-1723. PMid:19560124. http:// dx.doi.org/10.1016/j.carres.2009.05.028

25. Santana SAA, Vieira AP, Silva Filho EC, Melo JCP and Airoldi C. Immobilization of ethylenesulfide on babassu coconut epicarp and mesocarp for divalent cation sorption. Journal of Hazardous Materials. 2010; 174:714-719. PMid:19836886. http://dx.doi.org/10.1016/j.jhazmat.2009.09.109

26. Arakaki LNH, Alves APM, Silva Filho EC, Fonseca MG, Oliveira SF, Espínola JGP et al. Sequestration of $\mathrm{Cu}(\mathrm{II})$, $\mathrm{Ni}(\mathrm{II})$, and $\mathrm{Co}(\mathrm{II})$ by ethyleneimine immobilized on silica. Thermochimica Acta. 2007; 453:72-74. http://dx.doi. org/10.1016/j.tca.2006.10.016

27. Arakaki LNH, Fonseca MG, Silva Filho EC, Alves APM, Sousa KS and Silva ALP. Extraction of $\mathrm{Pb}(\mathrm{II}), \mathrm{Cd}(\mathrm{II})$, and $\mathrm{Hg}(\mathrm{II})$ from aqueous solution by nitrogen and thiol functionality grafted to silica gel measured by calorimetry. Thermochimica Acta. 2006; 450:12-15. http://dx.doi. org/10.1016/j.tca.2006.06.012

28. Oliveira FJVE, Silva Filho EC, Melo Junior MA and Airoldi C. Modified coupling agents based on thiourea, immobilized onto silica. Thermodynamics of copper adsorption. Surface Science. 2009; 603:2200-2206. http://dx.doi.org/10.1016/j. susc.2009.04.020

29. Fonseca MG, Silva Filho EC, Machado Junior RSA, Arakaki LNH, Espínola JGP and Airoldi C. Zinc phyllosilicates containing amino pendant groups. Journal of Solid State Chemistry. 2004; 177:2316-2322. http://dx.doi.org/10.1016/j. jssc.2004.02.026

30. Morais CC, Silva Filho EC, Silva OG, Fonseca MG, Arakaki LNH and Espínola JGP. Thermal characterization of modified phyllosilicates with aromatic heterocyclic amines. Journal of Thermal Analysis and Calorimetry. 2007; 87:767-770. http:// dx.doi.org/10.1007/s10973-006-7854-1

31. Lee YC, Kim EJ, Yang JW and Shin HJ. Removal of malachite green by adsorption and precipitation using aminopropyl functionalized magnesium phyllosilicate. Journal of Hazardous Materials. 2011; 192:62-70. PMid:21616589.

32. Machado MO, Lopes ECN, Sousa KS and Airoldi C. The effectiveness of the protected amino group on crosslinked chitosans for copper removal and the thermodynamics of interaction at the solid/liquid interface. Carbohydrate Research. 2009; 77:760-766.

33. Fan L, Luo C, Lv Z, Lu F and Qiu H. Preparation of magnetic modified chitosan and adsorption of $\mathrm{Zn} 2+$ from aqueous solutions. Colloids and Surface B. 2011; 88:574-581. PMid:21868204. http://dx.doi.org/10.1016/j.colsurfb.2011.07.038

34. Silva OG, Fonseca MG and Arakaki LNH. Silylated calcium phosphates and their new behavior for copper retention from aqueous solution. Colloids and Surface A. 2007; 301:376-381. http://dx.doi.org/10.1016/j.colsurfa.2006.12.072

35. Silva OG, Silva Filho EC, Fonseca MG, Arakaki LNH and Airoldi C. Hydroxyapatite organofunctionalized with silylating agents for heavy cation removal. Journal of Colloid and Interface Science. 2006; 302:485-491. PMid:16904683. http:// dx.doi.org/10.1016/j.jcis.2006.07.010

36. Daković A, Kragović M, Rottinghaus GE, Sekulić Ž, Milićević $\mathrm{S}$, Milonjić SK et al. Influence of natural zeolitic tuff and organozeolites surface charge on sorption of ionizable fumonisin $\mathrm{B}_{1}$. Colloids and Surface B. 2010; 76:272-278. PMid:20004084. http://dx.doi.org/10.1016/j.colsurfb.2009.11.003

37. Awwad NS, Gad HMH, Ahmad MI and Aly HF. Sorption of lanthanum and erbium from aqueous solution by activated carbon prepared from rice husk. Colloids and Surface B. 2010; 81:593-599. PMid:20800456. http://dx.doi. org/10.1016/j.colsurfb.2010.08.002

38. Aochi YO and Farmer WJ. Effects of surface charge and particle morphology on the sorption/desorption behavior of water on clay minerals. Colloids and Surface A. 2011; 374:22-32. http:// dx.doi.org/10.1016/j.colsurfa.2010.10.039

39. Silva MLCP, Silva GLJP and Villela Filho DN. Hydrous tantalum phosphates for ion exchange purposes. A systematic study. Materials Research. 2002; 5:71-75. http://dx.doi. org/10.1590/S1516-14392002000100012

40. Biskup B and Subotic B. Kinetic analysis of the exchange process between sodium ions from zeolite A and cadmium, copper and nickel ions from solutions. Separation and Purification Technology. 2004; 37;17-31. http://dx.doi. org/10.1016/S1383-5866(03)00220-X 
41. Chen P-Y. The assessment of removing strontium and cesium cation from aqueous solution based on the combined methods of ionic liquid extraction and electrodeposition. Electrochimica Acta. 2007; 52:5484-5492. http://dx.doi.org/10.1016/j. electacta.2007.03.010

42. Oztekin Y and Yazicigil Z. Recovery of metals from complexed solutions by electrodeposition. Desalination. 2006; 190:79-88. http://dx.doi.org/10.1016/j.desal.2005.07.017

43. Mokone TP, Lewis AE and van Hille RP. Effect of post-precipitation of colloidal metal sulphide precipitates. Hydrometallurgy. 2012; 119-120:55-66. http://dx.doi. org/10.1016/j.hydromet.2012.02.015

44. Mokone TP, van Hille RP and Lewis AE. Effect of solution chemistry on particle characteristics during metal sulfide precipitation. Journal of Colloid and Interface Science. 2012; 351:10-18. PMid:20705300. http://dx.doi. org/10.1016/j.jcis.2010.06.027

45. Al-Abri M, Dakheel A, Tizaoui C and Hilal N. Combined humic substance and heavy metals coagulation, and membrane filtration under saline conditions. Desalination. 2010; 253:46-50. http:// dx.doi.org/10.1016/j.desal.2009.11.037

46. Henneberr YK, Kraus TEC, Fleck JA, Krabbenhoft DP, Bachand PM and Horwath WR. Removal of inorganic mercury and methylmercury from surface waters following coagulation of dissolved organic matter with metal-based salts. Science of the Total Environmental. 2011; 409:631-637. PMid:21075424. http://dx.doi.org/10.1016/j.scitotenv.2010.10.030

47. Langmuir IJ. The constitution and fundamental properties of solids and liquids, Part 1. Solids. Journal of the American Chemical Society. 1916; 38:2221-2295. http://dx.doi. org/10.1021/ja02268a002

48. Freundlich HMF. Über die adsorption in Lösungen. Physics Chemistry. 1906; 57A:385-470.

49. Temkin MJ and Pyzhev V. Recent modification to Langmuir isotherms. Acta Physics URSS. 1940; 12:217-225.

50. Sales JAA, Faria FP, Prado AGS and Airoldi C. Attachment of 2-aminomethylpyridine molecule onto grafted silica gel surface and its ability in chelating cations. Polyhedron. 2004; 23:719-725. http://dx.doi.org/10.1016/j. poly.2003.11.051

51. Oh SY, Yoo DI, Shin Y and Seo G. FTIR analysis of cellulose treated with sodium hydroxide and carbon dioxide. Carbohydrate Research. 2005; 340:417-428. PMid:15680597. http://dx.doi.org/10.1016/j.carres.2004.11.027

52. Pavia DL, Basser GM and Morrill TC. Introduction to Spectroscopy. 2nd ed. Saunder: College Publishing, New York; 1996.

53. Kono H, Yunoki S, Shikano T and Fujiwara T. CP/MAS ${ }^{13} \mathrm{CNMR}$ study of cellulose and cellulose derivatives. 1. Complete assignment of the CP/MAS ${ }^{13} \mathrm{C}$ NMR spectrum of the native cellulose. Journal of the American Chemical Society. 2002; 124:506-7511. PMid:12071760. http://dx.doi. org/10.1021/ja010704o

54. Kasuya N, Suzuki T and Sawatari A. Studies on the thermal properties and structures of deoxyhalocelluloses. Journal of Wood Science. 1999; 45:161-163. http://dx.doi.org/10.1007/ BF01192334

55. Lima IS and Airoldi C. A thermodynamic investigation on chitosan-divalent cation interactions. Thermochimica Acta. 2004; 421:133-139. http://dx.doi.org/10.1016/j. tca.2004.03.012

56. Airoldi $\mathrm{C}$ and Arakaki LNH. Immobilization of ethylenesulfide on silica surface through sol-gel process and some thermodynamic data of divalent cation interactions. Polyhedron. 2001; 20:929-936. http://dx.doi.org/10.1016/ S0277-5387(01)00743-4

57. Giles CH, Macewan TH, Nakhwa SN and Smith DJ. Studies in adsorption. XI. A system of classification of solution adsorption isotherms. Journal of the Chemical Society. 1960; 1:3973-3993. http://dx.doi.org/10.1039/jr9600003973

58. Warner JC, Cannon AS and Dye KM. Green Chemistry. Environmental Impact Assessment Review. 2004; 24:775-799. http://dx.doi.org/10.1016/j.eiar.2004.06.006 